\title{
The impact of supply shocks on unemployment in Spain
}

\author{
Juan Carlos Cuestas* \\ Eesti Pank, Research Unit, and Tallinn University of Technology, Dept. of Finance and Economics, Estonia
}

Received: 27 June 2016

Revised: 24 August 2016

Accepted: 26 August 2016

\begin{abstract}
In this paper we aim to investigate how the relationships of falls and rises in the oil price with the unemployment rate and the equilibrium unemployment rate differ in the case of Spain. It is found that while oil price movements do not have an effect on unemployment, they do have a differential effect on the equilibrium rate of unemployment for our target country.
\end{abstract}

Keywords: unemployment rates; oil prices shocks; asymmetries.

JEL Classification Codes: C22, E39, Q43

\section{Introduction}

The behaviour of the Spanish unemployment rate is an interesting case study, as it has historically been very high. The problem became very serious after the 2007 financial crisis ignited and the unemployment rate jumped from a low of $7.9 \%$ in May 2007 to $26.3 \%$ in July 2013, despite the austerity measures deployed by the elected government in November 2011, which were aimed at reducing budget deficits, increasing investment and reactivating the economy.

Spain is a net importer of oil and so developments in oil prices in the last few years may have generated a supply shock with effects on the unemployment dynamics in the country. This is so since oil price shocks may affect the unemployment rate in equilibrium, as established by Hamilton $(1983,1988)$ and Carruth et al. (1998). In this paper we focus on the effect of positive and negative supply shocks on the unemployment rate in Spain rather than on GDP per capita or growth in GDP for two reasons; first, as established by Okun (1962), not all changes in GDP are transmitted to job creation or destruction. Second, unemployment is, in general, a social problem and many indicators of well-being consider unemployment as a key variable. This is particularly important in Spain since measures to tackle this structural problem have been, in the best case, unsuccessful. Hence this paper may be informative for policy makers and

\footnotetext{
*E-mail: juan.carlos.cuestas@eestipank.ee.

Citation: Cuestas, J.C. (2016) The impact of supply shocks on unemployment in Spain, Economics and Business Letters, 5(4), 107-112.
} 
institutions alike on the importance of supply shocks when designing policies to tackle unemployment.

The reasons for considering the possibility of asymmetries in the effect of oil price changes on unemployment are twofold; (1) the effect of falls in oil prices on unemployment may be different in magnitude to that of rises in oil prices because of rigidities in the downward movements of prices and wages; and (2) econometrically we may gain in robustness as we are incorporating more information in the model. The asymmetries of the effects of oil price movements on macroeconomic variables have been considered within the literature, as in Jiménez-Rodríguez and Sánchez (2005), Jiménez-Rodríguez (2009) and Cuestas and Gil-Alana (2016). (See also Acurio-Vásconez, 2015, and Bampinas and Panagiotidis, 2015).

There are a number of articles which have analysed the effect of oil price shocks on unemployment, such as Andreopoulos (2009), Caporale and Gil-Alana (2002) and Gil-Alana (2003, 2006), and they find in general that oil price changes have a significant and negative effect on unemployment rates. For the case of Spain however, to the best of our knowledge only Estrada and Hernández de Cos (2012) have analysed the effect of oil price shocks on macro variables, amongst them the unemployment rate in equilibrium. However, the authors based their analysis on simple OLS regressions without considering the order of integration of the variables, and without controlling for the differential effect of rises and falls in the price of oil.

In this paper, we analyse the asymmetric effect of positive and negative changes in the price of oil on unemployment for the case of Spain, using the Nonlinear Autoregressive Distributed Lag (NARDL) developed by Pesaran et al. (2001) and Shin et al. (2014), which allows us to include $\mathrm{I}(1)$ and $\mathrm{I}(0)$ variables in the same model. We also distinguish between the effect on the unemployment rate and the equilibrium unemployment rate proxied by the Hodrick-Prescott filter, as in the Carruth et al. (1998) model.

The rest of the paper is organised as follows. In the next section, we summarise the theoretical and econometric model used in this empirical analysis. Section 3 contains the data description and the econometric results. Finally, the last section concludes the paper.

\section{Economic and econometric modelling}

Here we use the model developed by Carruth et al (1998), who established that the link between oil prices and unemployment in equilibrium comes from the efficiency-wage framework. In a nutshell, an increase in the oil price increases the cost of production. When this happens, firms may be forced to fire workers in order to minimise the increase in costs and re-establish profit maximisation, and this may at the same time force the remaining workers to accept a reduction in real wages. This will then increase the unemployment rate in equilibrium.

The econometric analysis is based on the NARDL model developed by Pesaran et al. (2001) and Shin et al. (2014), as follows:

$$
\begin{gathered}
\Delta u_{t}=c+\alpha_{0} u_{t-1}+\alpha_{1}^{+} p_{t-1}^{+}+\alpha_{1}^{-} p_{t-1}^{-}+\theta_{i} \sum_{i=1}^{p} \Delta u_{t-i}+\gamma_{i}^{+} \sum_{i=1}^{q} \Delta p_{t+1-i}^{+} \\
+\gamma_{i}^{-} \sum_{i=1}^{q} \Delta p_{t+1-i}^{-}+\varepsilon_{t}
\end{gathered}
$$

where

$$
p_{t}^{+}=\sum_{j=1}^{T} \max \left(\Delta p_{t}, 0\right)
$$


represents rises in the price of oil,

$$
p_{t}^{-}=\sum_{j=1}^{T} \min \left(\Delta p_{t}, 0\right)
$$

represents falls in the price of oil, and $u_{t}$ is the unemployment rate or equilibrium unemployment rate. If the alphas are divided by $-\alpha_{0}$, the long-run relationship can be tested with a bond test on the null $H_{0}: \beta_{0}=\beta_{1}^{+}=\beta_{1}^{-}=0$, where the $\beta$ s are the new parameters after dividing by $-\alpha_{0}$. The possibility of long-run and short-run asymmetries can be tested with a Wald test with the null hypothesis of

$$
H_{0}: \alpha_{1}^{+}=\alpha_{1}^{-}
$$

and

$$
H_{0}: \sum_{i=0}^{q-1} \gamma=\sum_{i=0}^{+} \gamma_{i}
$$

for the long run and the short run respectively. ARDL models have the advantage that $\mathrm{I}(0)$ and I(1) variables can be included in the same equation.

In this paper we also display graphical representations of the dynamic multipliers. These multipliers show the effect on the unemployment rate of a unit change in $p_{t}^{+}$and $p_{t}^{-}$. The cumulative dynamic multiplier effects are

$$
m_{h}^{+}=\sum_{j=0}^{h} \frac{\partial u_{t+j}}{\partial p_{t}^{+}}
$$

and

$$
m_{h}^{-}=\sum_{j=0}^{h} \frac{\partial u_{t+j}}{\partial p_{t}^{-}}
$$

for $h=0,1,2, \ldots$ (see Shin et al. 2014 for further details).

\section{Data and results}

The data for Spanish unemployment consist of monthly seasonally adjusted unemployment rates for the period 1997M12-2016M4, obtained from Eurostat series une_rt_m. Data for oil prices, $p_{t}$, have been obtained from the US Energy Information Administration, and the Brent Spot Price FOB (Dollars per Barrel) is used for Europe. The nominal price has been deflated with the US harmonised index of consumer prices from Eurostat, series ei_cphi_m. The reason for using the real oil price in dollars is to avoid fluctuations in exchange rates which may have nothing to do with supply shocks filtering into the system. It also lets us avoid endogeneity issues. The analysis has been carried out with both variables in natural logs, with two years of lags in the NARDL. Note that the real oil price in this case can be treated as exogenous since it is measured in US dollars and deflated by the US harmonised index of consumer prices. This justifies the use of reduced form analysis. The series are reproduced in Figure 1. It is clear that until 2007 there was a negative correlation between unemployment and the oil price, but the sign of the correlation seems to change after 2008. In addition, it seems that since 2010 oil price movements have clearly preceded changes in the unemployment rate. 
Figure 1. The unemployment rate and the oil price.

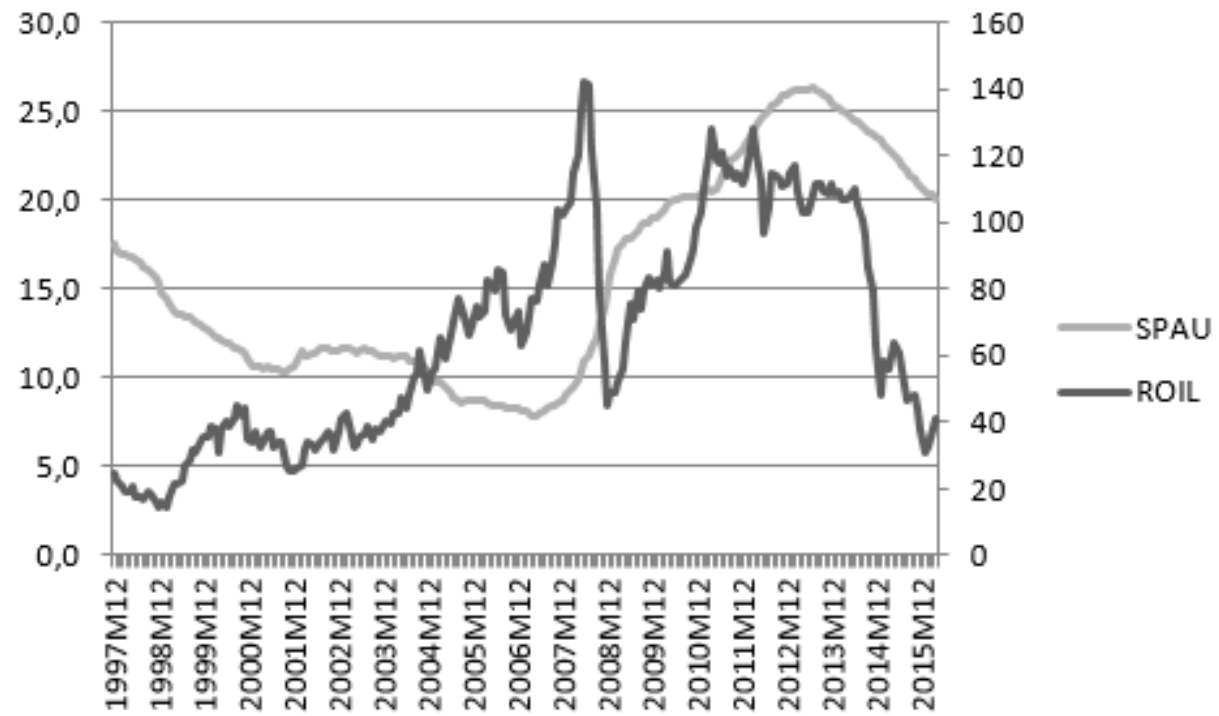

Note: The right axis indicates the real oil price in dollars, the left axis the unemployment rate in $\%$.

Table 1. Long-run effects based on a NARDL.

\begin{tabular}{ccccccc}
\hline \hline & \multicolumn{3}{c}{ Long-run effect $(+)$} & \multicolumn{3}{c}{ Long-run effect (-) } \\
\hline \hline Definition & Coef. & F-stat & p-value & Coef. & F-stat & p-value \\
Unemployment & 0.779 & 0.279 & 0.598 & -0.845 & 0.209 & 0.648 \\
HP unemployment & 1.498 & 6.887 & 0.010 & -1.665 & 5.731 & 0.018 \\
\hline \hline
\end{tabular}

Table 2: Test for asymmetric effects.

\begin{tabular}{clccc}
\hline \hline & \multicolumn{2}{l}{ Long-run asymmetry } & \multicolumn{2}{c}{ Short-run asymmetry } \\
\hline \hline Definition & F-stat & p-value & F-stat & p-value \\
Unemployment & 0.028 & 0.866 & 0.26 & 0.606 \\
HP unemployment & 1.478 & 0.226 & 11.81 & 0.001 \\
\hline \hline
\end{tabular}

In Table 1, we display the long-run effect of a positive change and a negative change in the oil price on both the unemployment rate and the equilibrium unemployment rate obtained by means of the Hodrick-Prescott procedure. As shown, neither rises nor falls in the price of oil have an effect on the unemployment rate. This conclusion is corroborated by Figure 2, where we display the dynamic multiplier effects. As may be noticed, the grey area contains the zero line for the 25 periods plotted.

However, when we look at the effect of changes in the price of oil on the equilibrium unemployment rate, we find a different response. Both rises and falls in the price of oil have a long-run effect on the equilibrium unemployment rate, as predicted by Carruth et al. (1998), and the effects are of a very similar magnitude. This may be a sign that the magnitude of the effect on the equilibrium rate of unemployment of a rise in the price of oil is similar to that of a fall. This conclusion is corroborated by Table 2, as the long-run asymmetry test indicates non-rejection of the null of symmetric effects in the long run. Interestingly, there seems to be an asymmetric effect in the dynamics, as the null of symmetric effects is rejected at the $5 \%$ significance level. This depicts an interesting feature of our data; in the short run it appears that there are rigidities which prevent a full pass-through of falls in the oil price to the equilibrium 
unemployment rate. However, in the long-run those rigidities disappear and the asymmetric effect vanishes.

The overall effect is shown in Figure 3. As the figure shows, the overall effect of a rise in the price of oil is more damaging than that of a fall.

Figure 2. Cumulative effects on unemployment.

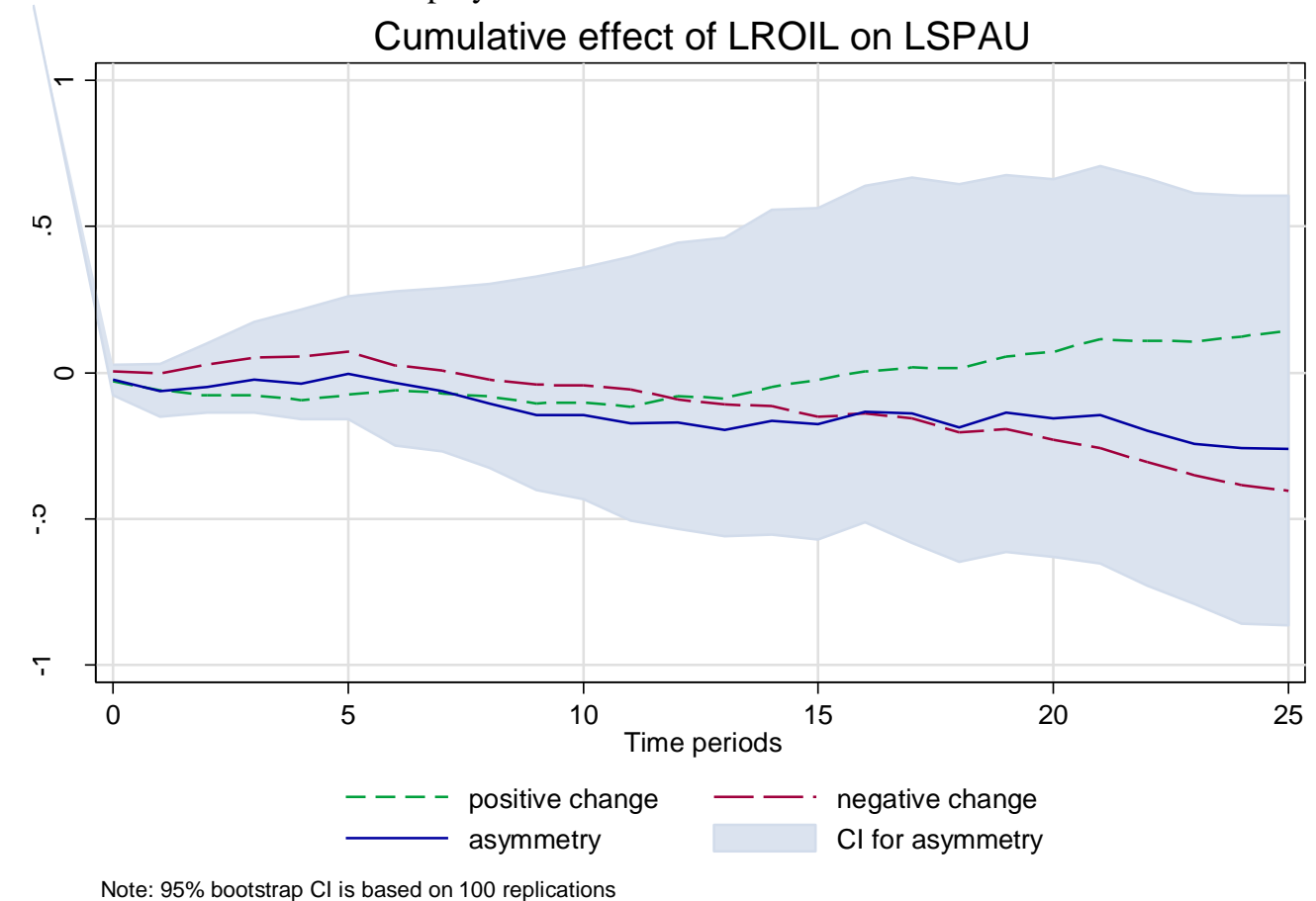

Figure 3. Cumulative effects on the unemployment trend.

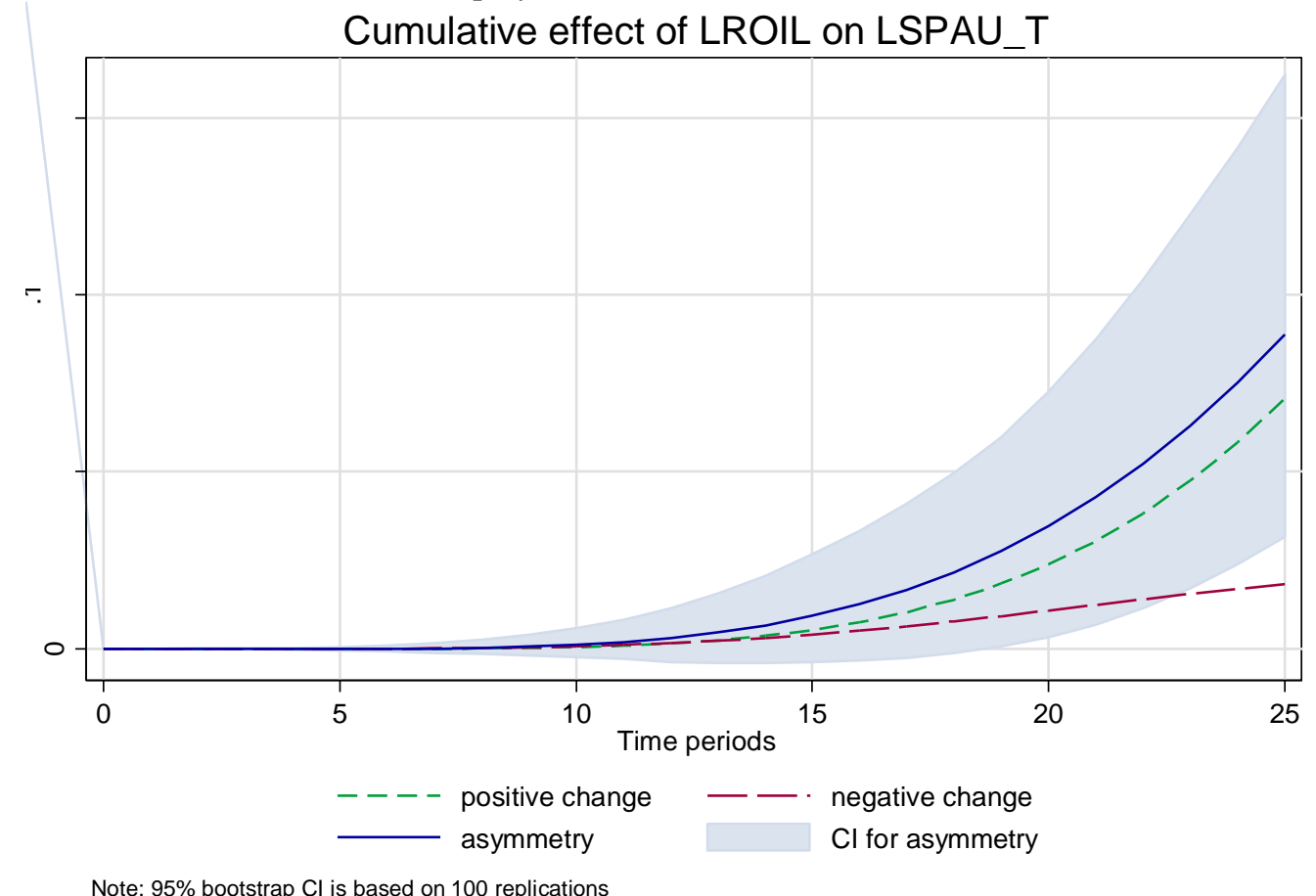

\section{Conclusions}

Following from the recent controversy about whether the sudden oil price falls in 2013-2015 may have had a detrimental effect on GDP and unemployment, we have analysed the potential 
asymmetric effect of oil price movements on the unemployment rate of Spain. Our results show that although supply shocks do not seem to have an effect on the unemployment rate, they do have an effect on the equilibrium unemployment rate. The effect on the equilibrium rate of unemployment of a rise in the price of oil is stronger and more damaging than the effect of a fall in the price of oil.

Disclaimer and acknowledgements. The views expressed are those of the author and do not necessarily represent the official views of Eesti Pank or the Eurosystem. The author gratefully acknowledges comments from two anonymous referees and the associate editor Theorodos Panagiotidis. The financial support from the MINECO (Ministerio de Economía y Competitividad, Spain) research grant ECO201458991-C3-2-R and the Generalitat Valenciana project AICO/2016/038 is also acknowledged.

\section{References}

Acurio-Vásconez, V. (2015) Oil and Unemployment in a New-Keynesian Model, Documents de Travail du Centre d'Economie de la Sorbornne no. 2015.43.

Bampinas, G. and Panagiotidis, T. (2015) On the relationship between oil and gold before and after financial crisis: linear, nonlinear and time-varying causality testing, Studies in Nonlinear Dynamics and Econometrics, 19, 657-668.

Caporale, G.M. and Gil-Alana, L. (2002) Unemployment and input prices: a fractional cointegration approach, Applied Economics Letters, 9, 347-351.

Carruth, A.A., Hooker, M.A. and Oswald, A.J. (1998) Unemployment equilibria and input prices: Theory and evidence from the United States, Review of Economics and Statistics, $80,621-628$.

Cuestas, J.C. and Gil-Alana, L.A. (2016) Oil shocks on unemployment in Central and Eastern Europe, School of Economics and Business Administration, Faculty Working Papers 02/16, University of Navarra.

Estrada, A., and Hernández de Cos, P. (2012) Oil prices and their effect on potential output, Applied Economics Letters, 19, 207-214.

Gil-Alana, L.A. (2003) Unemployment and real oil prices in Australia: a fractionally cointegrated approach, Applied Economics Letters, 10, 201-204.

Gil-Alana, L.A. (2006) UK Unemployment Dynamics: a Fractionally Cointegrated Approach, Economia Internazionale / International Economics, Camera di Commercio di Genova, 59, 33-50.

Hamilton, J.D. (1983) Oil and the macroeconomy since World War II, Journal of Political Economy, 91, 228-248.

Hamilton, J.D. (1988) A neoclassical model of unemployment and the business cycle, Journal of Political Economy, 96, 593-617.

Jiménez-Rodríguez, R. (2009) Oil Price Shocks and Real GDP Growth: Testing for Non-Linearity, Energy Journal, 30, 1-23.

Jiménez-Rodríguez, R. and Sánchez, M. (2005) Oil Price Shocks and Real GDP Growth: Empirical Evidence for Some OECD Countries, Applied Economics, 37, 201-228.

Okun, A.M. (1962) Potential GNP: Its measurement and significance, Proceedings of the Business and Economics Statistics Section of the American Statistical Association, 98-104.

Pesaran, M.H., Shin, Y. and Smith, R.J. (2001) Bounds testing approaches to the analysis of level relationships, Journal of Applied Econometrics, 16, 289-326.

Shin, Y., Yu, B. and Greenwood-Nimmo, M. (2014) Modelling asymmetric cointegration and dynamic multipliers in a nonlinear ARDL framework, Festschrift in Honor of Peter Schmidt, Springer, 281-314. 